\title{
Prevalence of Anaplasma ovis infection in Angora goats of Duhok province, Kurdistan region-Iraq
}

\begin{abstract}
I.A. Naqid
Department of Veterinary Medicine and Surgery, College of Veterinary Medicine and Science, University of Duhok, Duhok, Kurdistan Region, Iraq, Email: ibrahim.naqid@uod.ac, Tel: 009647504737593
\end{abstract}

(Received May 30, 2017; Accepted July 13, 2017)

\begin{abstract}
Acute Anaplasma ovis infections can cause severe clinical symptoms and might lead to significant economic losses in small ruminant flocks. However, little information has been provided related the prevalence of anaplasmosis in Angora goats. The study was designed to investigate the prevalence of Anaplasma ovis serologically (cELISA) and microscopically (Giemsa stained blood smears) among Angora goats from Duhok districts of the northern part of Iraq. A total of 92 blood samples were randomly collected from three localities of Duhok city; Zakho, Batel and Sumil during the study period from April to October 2009. The infection rate of $A$. ovis was $38.04 \%$ by Giemsa stained blood smear and $66.3 \%$ by cELISA. The prevalence of $A$. ovis in female goats was higher than that in males, but statistically not significant difference $(\mathrm{P}>0.05)$ by using both methods. The prevalence was also significantly higher $(\mathrm{P}<0.05)$ in goats more than three years old than in younger ones. The highest prevalence of $A$. ovis was found in Zakho, whereas the lowest was reported in Sumail. Results of hematological parameters indicated microcytic hypochromic type of anemia.It is concluded that A. ovis can infected Angora goats in district Duhok, Kurdistan region, Iraq and this might be due to high distribution of the disease and its transmitters which were lead to substantial effect followed by high mortalities
\end{abstract}

Keywords: Anaplasma ovis, cELISA, Hematology, Diagnosis, Angora goat Available online at http://www.vetmedmosul.org/ijvs

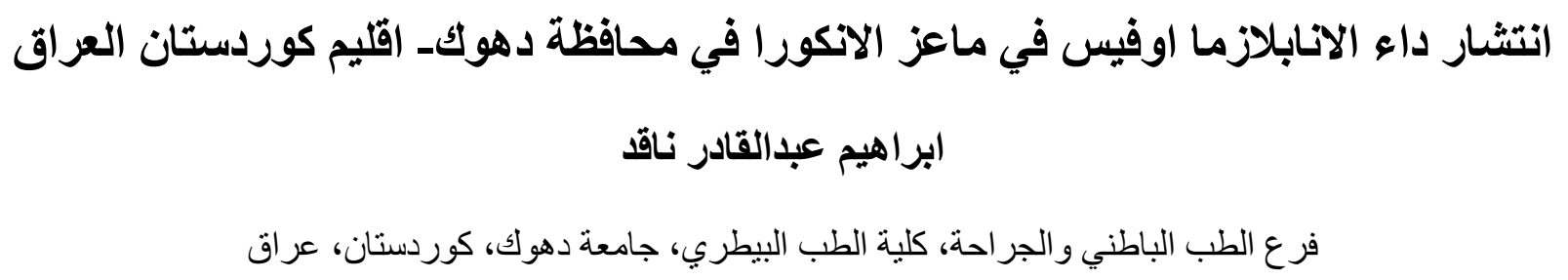

الخلاصة

يسبب داء الانابلازموسز الحاد علامات سريرية شديدة قد تؤدي الى هلاك الحيوان المصاب و خسائر اقتصادية كبيرة في قطعان

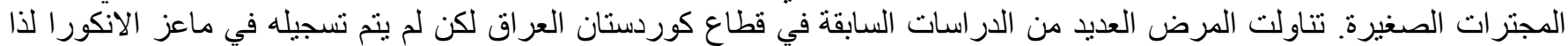

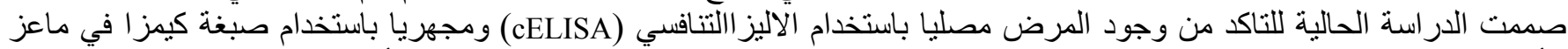

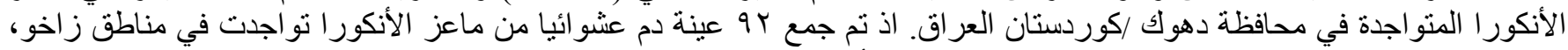

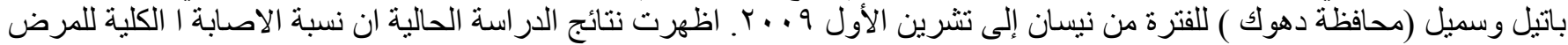

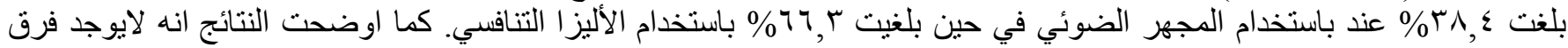

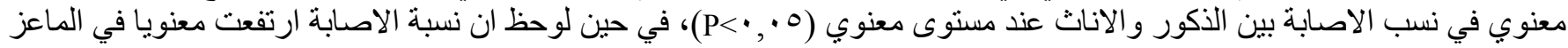

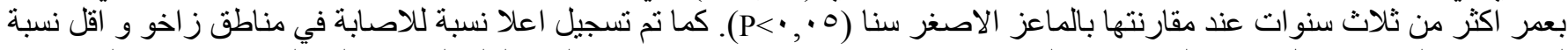

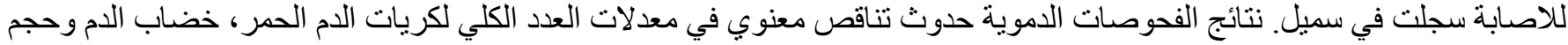

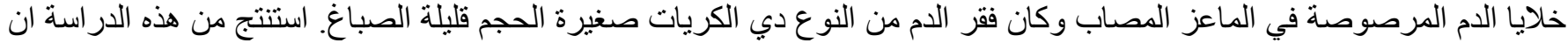

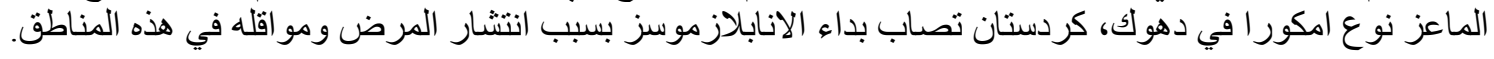




\section{Introduction}

Anaplasmosis is one of the important worldwide distributed tick-borne diseases of ruminant livestock in tropical and subtropical regions of the world with a great economic impact $(1,2)$. The genus Anaplasma includes $A$. marginale, A. central, A. ovis, and A. bovis, which infect ruminants; A. platys, which infects dogs; and $A$. phagocytophilum, which infects several mammalian species (3). In the case of A. ovis, rickettsial inclusions are found $35-40 \%$ of the time in the central or sub-marginal part of the host erythrocyte, and the remaining $60-65 \%$ in the marginal part. Anaplasmosis is transmitted mechanically by lice, biting flies and blood contaminated fomites (4) and biologically by various tick species such as Boophilus, Dermacentor, Rhipicephalus, Hyaloma, Ixodes, and Ornithodoros (5). The acute stage of the disease is characterized by weight loss, fever, and pale mucous membrane, jaundice and decreased milk production and often death (4). Although $A$. ovis is more frequently associated with haemolytic anaemia in goats, it can also cause disease in sheep, particularly in animals exposed to stress or other predisposing factors such as drought and heavy tick infestation promote clinical cases of $A$. ovis, and it is likely that the pathogen contributes to economic losses to the livestock industry (5).

During the acute stage of the infection, the diagnosis of A. ovis in small ruminants is usually made on the basis of clinical signs, the presence of the parasite in stained blood smears and hematological changes during infection (6). However, percentages of parasitemia in carriers' state of less than $0.1 \%$ infected erythrocytes are not dependably detected by microscopical examination (6). The detection of carriers is important for epidemiological studies as well as for planning disease prevention and control strategies. For this reason, several serological diagnostic assays have been increasingly used to detect Anaplasma species in carrier animals, but diagnostic performance of different assays is highly variable due to antigenic similarity. Such diagnostic assays have been applied to detect carrier animals including card agglutination test (7), indirect enzyme-linked immunosorbent assay (ELISA) (8), and dot ELISA (9). However, there were problems of sensitivity, reproducibility, interpretation and non-specific interactions associated with these serological tests. Recently, a competitive inhibition enzyme-linked immunosorbent assay (cELISA) based on Major Surface Protein 5 (MSP-5) of A. marginale have been successfully used for the detection of antibodies against Anaplasma spp. $(10,11)$. This serological test has significant advantage than other tests because of greater sensitivity $96 \%$ and specificity $95 \%$ for diagnosis of anaplasmosis (11). There exist very scanty information were available on the serological survey of $A$. ovis infection in goats using cELISA in Kurdistan Region-Iraq. It has been previously reported that the prevalence of $A$. ovis in local goats in Duhok province, Kurdistan Region, Iraq using competitive ELISA and Giemsa stained blood smears (12). As Angora goats are primarily raised for the production of milk, meat and colorful fiber known as mohair, which are a silky fiber used for producing Kurdish traditional clothes, there is an increasing demand for a better understanding of the diseases affecting these animals as they seem to contribute to a decrease in productivity. Therefore, the objective of this study was for the first time to investigate the serological prevalence A. ovis in Angora goats using competitive ELISA based on MSP5 recombinant of $A$. marginale.

\section{Materials and methods}

\section{Study area and collection of samples}

This study was conducted on Angora goats in different localities in Duhok Government (Zakho, Sumail and Batel), Kurdistan Region in Northern Iraq for the period from April to October 2009. Blood sampling was performed in suspicious farms with the history of the outbreak of tickborne diseases and in Angora goats with tick infestation. 10 $\mathrm{ml}$ of Blood were collected via jugular vein puncture of 92 Angora goats (20 males and 72 females) for microscopic examination and serological test and divided into two parts.

One part was added to non-heparinised vacutianer tubes and then incubated at ambient temperature for at least $2 \mathrm{hr}$ to allow clotting. Blood samples were then centrifuged at $4000 \mathrm{~g}$ for $5 \mathrm{~min}$ to collect the sera which were stored at $20{ }^{\circ} \mathrm{C}$ until use. The second part of blood was applied in heparinised vacutianer tube and used for the estimation of hematological parameters in order to classified type of anemia such as total erythrocyte count (RBC), packed cell volume (PCV), hemoglobin concentration $(\mathrm{Hb})$, mean corpuscular volume (MCV), mean corpuscular hemoglobin $(\mathrm{MCH})$, and mean corpuscular hemoglobin concentration (MCHC) as described by Meyer and Harvey (13).

\section{Microscopic examinations}

Giemsa stain blood smears were used for microscopical detection of causative agent according to (14). Briefly, Blood smears were fixed with $70 \%$ methanol for five minutes, stained with Giemsa at a dilution of $10 \%$ in distal water for $30 \mathrm{~min}$, and then examined for the presence of $A$. ovis inclusion bodies under oil immersion lens $(100 \times)$. Blood smears were recorded as negative for $A$. ovis if no inclusion bodies were observed in a $20-30$ oil-immersion field.

\section{Serological diagnosis for the detection of A. ovis}

All sera collected from goats were tested for the presence of antibodies against Anaplasma by competitive ELISA (cELISA). The cELISA was performed with serum 
samples of 92 Angora goats using the Anaplasma Antibody Test Kit from VMRD Inc. (Pullman, WA, USA; Catalog number: 282-2) (15) following the manufactures' instructions. This serological assay detects serum antibodies to a major surface protein (MSP5) of A. marginale, A. centrale, and A. ovis (15). Although this commercial kit has been approved for using in bovines by the US Department of agriculture, it has also been used to detect antibodies against $A$. ovis in goats and experimentally infected sheep since the MSP5 epitope in conserved among the three Anaplasma species (16).

\section{Statistical analysis}

The Chi-square test and Fisher's exact test were applied to analyze significant differences between variables such as gender, sex and regions as well as hematological parameters using the GraphPad Prism software package, version 6.2. $P$-values $<0.05$ were considered statistically significant.

\section{Results}

\section{Analysis of blood smears}

Microscopic examination of 92 blood smears from three different area of Duhok province revealed that 35 (38.04\%) of goats were infected with Anaplasma like inclusion bodies. According to morphological characteristics, Anaplasma inclusion bodies appeared as one uniform dark staining dote like circular bodies on the periphery to the infected goat erythrocytes (Figure 1).

The highest prevalence was observed in the Sumail region with $42.1 \%(16 / 38)$ and the lowest was reported in the Batel region with $25 \%$ (4/16), while in Zakho region was $39.47 \%(15 / 38)$ (Table 1). According to the age of animals, the highest prevalence of A. ovis was $66.6 \%$ $(22 / 33)$ in age group more than 3 years and lowest prevalence was $25 \%(2 / 8)$ in age group less than 1 year, while in age group 1-3 years was 21.6\% (11/51) (Table 2). With regard to gender of animals, the infection rate was $40.27 \%(29 / 72)$ in females and $30 \%(6 / 20)$ in males as shown in table (3).

\section{Serological diagnosis of $A$. ovis by CI-ELISA}

Out of 92 serum samples, 61 (66.3\%) of Angora goats serum samples were found seropositive for $A$. ovis infection in three districts of Duhok province since, 29 (76.3\%), 21 $(55.26 \%)$ and $11(68.75 \%)$ were detected at Zakho and Sumail and Batel area, respectively (Table 1). According to the animal ages, the seroprevalence was $4(50 \%), 31$ $(60.78 \%)$ and $26(78.78 \%)$ in the age $<1$ year, 1 -3years, and $>3$ years, respectively (Table 2 ) with statistically significant difference at level $(\mathrm{P}<0.05)$. With regard to gender of animals, the seroprevalence rate was $12(60 \%)$ for male and 49 (68.1\%) for female (Table 3), but statistically not significant difference at level $(\mathrm{P}<0.05)$.

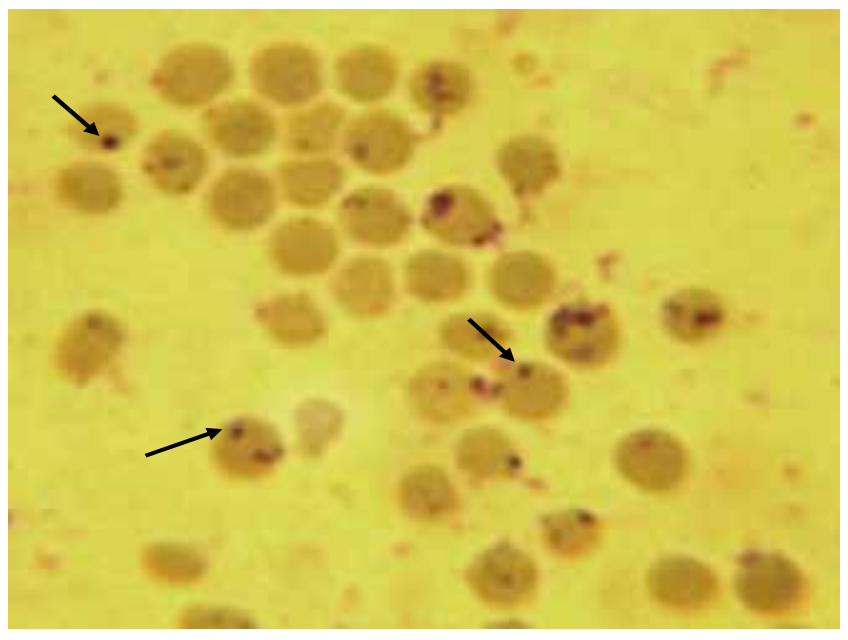

Figure 1: Anaplasma ovis inside goat erythrocytes Giemsa stain blood smears (1000x).

Table 1: Infection rate of $A$. ovis infected Angora goats according to different regions of Duhok governorate, Kurdistan region of Iraq

\begin{tabular}{|c|c|c|c|}
\hline \multirow[b]{2}{*}{ Location $^{\mathrm{a}}$} & \multirow{2}{*}{$\begin{array}{c}\text { No. of } \\
\text { goats } \\
\text { examined }\end{array}$} & \multicolumn{2}{|c|}{ Number of positive by: } \\
\hline & & $\begin{array}{l}\text { Microscopic } \\
\text { examination }^{\mathrm{b}}\end{array}$ & $\begin{array}{c}\text { MSP5 } \\
\text { cELISA }^{c} \\
\end{array}$ \\
\hline Zakho & 38 & $15(39.47 \%)$ & $29(76.3 \%)$ \\
\hline Sumail & 38 & $16(42.1 \%)$ & $21(55.26 \%)$ \\
\hline Batel & 16 & $4(25 \%)$ & $11(68.75 \%)$ \\
\hline Total & 92 & $35(38.04 \%)$ & $61(66.3 \%)$ \\
\hline
\end{tabular}

Table 2: Infection rate of Anaplasma ovis according to animal ages

\begin{tabular}{|c|c|c|c|}
\hline \multirow[b]{2}{*}{ Age } & \multirow{2}{*}{$\begin{array}{c}\text { No. of } \\
\text { goats } \\
\text { examined }\end{array}$} & \multicolumn{2}{|c|}{ Number of positive by: } \\
\hline & & $\begin{array}{l}\text { Microscopic } \\
\text { examination }\end{array}$ & $\begin{array}{c}\text { MSP5 } \\
\text { cELISA }\end{array}$ \\
\hline$<1$ year* & 8 & $2(25 \%)$ & $4(50 \%)$ \\
\hline $1-3$ years* & 51 & $11(21.6 \%)$ & $31(60.78) \%$ \\
\hline$>3$ years* & 33 & $22(66.6 \%)$ & $26(78.78 \%)$ \\
\hline Total & 92 & $35(38.04 \%)$ & $61(66.3 \%)$ \\
\hline
\end{tabular}

*Statistically significant difference between ages at a level of $P<0.01$. 
Table 3: Infection rate of Anaplasma ovis according to animal gender

\begin{tabular}{lccc}
\hline \multirow{2}{*}{ Gender* } & \multirow{2}{*}{$\begin{array}{c}\text { No. of } \\
\text { goats }\end{array}$} & \multicolumn{2}{c}{ Number of positive by: } \\
\cline { 3 - 4 } & examined & $\begin{array}{c}\text { Microscopic } \\
\text { examination }\end{array}$ & MSP5 \\
& 20 & $6(30 \%)$ & $12(60 \%)$ \\
Male & 72 & $29(40.27 \%)$ & $49(68.1 \%)$ \\
Female & 92 & $35(38.04 \%)$ & $61(66.3 \%)$ \\
\hline Total & 9
\end{tabular}

*No statistically significant difference at a level of $p<0.05$

\section{Hematological parameters}

Results of hematological parameters showed that significant decreased in RBC, $\mathrm{Hb}$, and PCV at a level of $(p<0.01)$ compared with non-infected animals which reflected microcytic hypochromic type of anemia (table 4).

Table 4: Hematological parameters of Angora goats infected with $A$. ovis infection

\begin{tabular}{lcc}
\hline Parameters & $\begin{array}{c}{ }^{\mathrm{a}} \text { Non-infected } \\
\text { animals }\end{array}$ & $\begin{array}{c}{ }^{\mathrm{b}} \text { Infected } \\
\text { animals }\end{array}$ \\
\hline $\mathrm{RBC} \mathrm{x}\left(10^{6} / \mu \mathrm{l}\right)$ & $12.98 \pm 0.84$ & $7.78 \pm 1.07^{* *}$ \\
$\mathrm{Hb}(\mathrm{g} / \mathrm{dl})$ & $8.03 \pm 0.74$ & $6.69 \pm 0.37^{* *}$ \\
$\mathrm{PCV} \mathrm{\%}$ & $24.8 \pm 4.38$ & $18.19 \pm 1.34^{* *}$ \\
$\mathrm{MCV}(\mathrm{fl})$ & $27.6 \pm 3.84$ & $14.91 \pm 1.39^{* *}$ \\
$\mathrm{MCH}(\mathrm{pg})$ & $9.32 \pm 2.01$ & $5.33 \pm 0.29^{* *}$ \\
$\mathrm{MCHC}(\mathrm{g} / \mathrm{dl})$ & $36.9 \pm 2.39$ & $30.66 \pm 1.8^{* *}$ \\
$\mathrm{~A}, \mathrm{~b}$ Values are mean \pm standard deviation of mean \\
**Statistically significant difference at a levels of $P<0.01$.
\end{tabular}

\section{Discussion}

Ovin anaplasmosis is important tick-borne rickettsial disease of domestic ruminant distributed in the tropical and subtropical regions worldwide. The disease is generally a subclinical or mild condition, but moderate to severe clinical disease is usually characterized by high fever and a variable degree of anemia and icterus that may occasionally lead to death (17).

Despite being an infection with a global distribution and significant economic impacts, ovin anaplasmosis remains largely neglected at the animal health agenda especially in small ruminant. Several previous studies have been undertaken in Iraq, but have more focused on local breeding goats and sheep $(12,18,19)$. Therefore, the aim of this study is to investigate A. ovis infection in Angora goats in Duhok province, Iraq using Giemsa staining and cELISA. Therefore, hematological parameters of the infected and non-infected animals were performed to investigate the effect of anaplasmosis on blood profile of the infected animals. The investigation of a parasite in the definitive host is essential for better understanding the epidemiology of the pathogen and designing appropriate strategies for its control.

In the current study, microscopic examination of Angora goat blood smears obtained from different districts in Duhok province, demonstrated that $38.04 \%$ of goats infected with $A$. ovis like inclusion bodies. This method has been commonly used in previous studies on ovine and caprine anaplasmosis prevalence $(20,21)$. The highest prevalence rate was found in Sumail region $42.1 \%$, followed by Zakho $39.47 \%$ and Batel $25 \%$, but statistically not significant differences among regions at level $(p<0.05)$. The distribution and abundance of vector ticks are affected by climatic conditions including humidity and temperature (22). These climatic conditions are favorable for the survival of vector ticks that transmit diseases, including Anaplasma spp., and these conditions could increase the possibility of tick borne disease spreading to livestock and wild animals; therefore resulting in a higher prevalence rate as observed in the present study.

Our previous study reported that the prevalence of $A$. ovis in local breeding goats was $55.86 \%$ in Duhok regions using Giemsa staining; this is higher than the prevalence in the present study (12). The reason may probably be due to Angora goats are usually living in hills or mountain area and the population of tick in this area is low and therefore the proportion of examined samples could be affected. Also, may be due to the ability of the Angora goat to pasture in inaccessible, unreachable and steep areas. In this condition is very difficult to have contact with ticks infected by feeding in other animal. Alsaad et al. (18) found the prevalence of A. ovis in local goats in Mousl province in Iraq revealed that $24.74 \%$ positive samples as detected using Giemsa staining. It has also reported by (23) that prevalence of $A$. ovis in Baghdad was $32.2 \%$ as determined by Giemsa staining.

The data were then observed after stratification of the goats by age, gender, and different regions. Adult goats revealed that a higher prevalence $(66.6 \%)$ compared with the young goats (25\%) and those of an age 1-3 (21.6\%). There was statistically significant difference in the prevalence rate in different age groups $(\mathrm{P}<0.05)$; a high rate was found in age group above 3 years in comparison to other age groups. The younger goats less susceptible to $A$. ovis infection than aged animals this could be due to passive immunization through maternal antibodies from dame to the kids via colostrum. This could also explained by the fact that adult goats were more exposed to tick infestation carry in $A$. ovis because they went through more tick seasons. One of the previous study reported that maternal antibodies against $\mathrm{A}$. marginal can be detected for 16 weeks of age in the calves (24). The prevalence of the $A$. ovis infection in goats was higher in the female $(40.278 \%)$ than in the male (30\%); this could be related to the proportion of the populations sampled. Furthermore, most 
of the farmers keep large number of females than males especially for breeding purposes which affected the proportion of the sex infected. Similarly, the findings of the present study are broadly consistent with the findings of our previous study conducted in Duhok Region, Iraq (12), who reported that female is more susceptible to infection than male. The explanation is that females are kept for a comparatively longer period within the breeding herd than is the case with males and so increase their chance of exposure to infections and also male animals are usually sold off at younger age than female. These results are in agreement with Friedhoff (5), who reported that many factors affecting the prevalence of Anaplasma spp infection including age, sex, and breed and also the clinical signs of the disease depend on age, and the general condition of the animals.

However, a limitation of microscopic examination (Giemsa stain blood smear) is their inability to differentiate the Anaplasma spp organism and other similar structures like Heinz bodies, Howell-Jolly bodies, or staining artifacts, which often seen in Giemsa stained blood smears need special experiences, especially in carrier animals with very low level of parasetemia (25). Giemsa stained blood smears can be indeed used as a suitable method to detect Anaplasma spp in the animals clinically suspected for acute stage of the diseases, but it is not applicable for the determination of pre-symptomatic animals (26). This makes microscopic analysis unreliable for the detection of persistent Anaplasma spp infections in carrier animals (27). Giemsa stained blood smears can be indeed used as a suitable method to detect Anaplasma in the animals clinically suspected for acute diseases, but it is not applicable for the determination of pre-symptomatic and carrier animals. To circumvent this problem, an alternative diagnostic technique, such as serological diagnostic tests (25) and nucleic acid-based assays (27) can be used for the detection of tick-borne parasites in carrier animals. Nevertheless, serological diagnostic assays tests could be more practical for the diagnosis of large number of tested animals than conventional microscopic test including Giemsa stained blood smear and also more sensitive and specific diagnostic tools to detect and differentiate Anaplasma species in carrier animals. Several studies have specified that cELISA test has very high sensitivity and specificity in the diagnosis of antibodies against Anaplasma species such as $A$. marginale as well as $A$. centrale, $A$. ovis and $A$. phagocytophilum (15). This cELISA is based on Major Surface Protein 5 (MSP-5) of A. marginale and has been successfully used to detect antibodies against Anaplasma spp such as A. centrale, $A$. ovis and $A$. phagocytophilum $(10,11)$.

In the present research, the seroprevalence of $A$. ovis in Angora goats in Duhok area by cELISA was $66.3 \%$ which is lower than our previous study reported in local goats in the same regions (75.22\%) (12). This difference of the seroprevalence might be due to the breed difference, geographical region size of flock and season of the study period. Anaplasmosis is generally progress to a lifelong persistent and subclinical infection, simultaneously providing the source for tick-borne transmission of the pathogen besides the widespread of ticks and other biting insects and also the absence of arthropod control; this may explain the high seroprevalence of ovine anaplasmosis (4). In present study, the highest prevalence was recorded in Zakho $76.3 \%$, followed by Batel $68.75 \%$, whereas the lowest prevalence recorded in Sumel 55.26\%. Among seropositive samples, $54.34 \%$ had a strong positive with $A$. ovis infection with inhibition value $\leq 70$, indicating that $A$. ovis is widely distributed in Duhok districts. The relatively high sero-prevalence rate of A. ovis observed in this study could be the cause of high tick vector population in Duhok area, which is greatly responsible for the transmission of the anaplasmosis. Renneker et al (20) reported a similar prevalence of $A$. ovis in sheep from Kurdistan region of Iraq revealed that $66.65 \%$ of sheep infected with anaplasmosis using a PCR-based detection approach. In other countries, anaplasmosis prevalence at much higher level i.e in Portugal (82.5\%), (20), in Kenya (89\%) (28), and in Iran (87.4\%) (14). However, prevalence rates reported for countries must be taken with caution since a standardized assay as sampling procedure was not applied in each study and rates of infection may vary even among neighboring farms. A lower prevalence rate $(27.5 \%)$ in goats has been reported in China (29), in Sudan and Turkey with $41.6 \%$ and $31.4 \%$, respectively, in sheep (Renneker et al., 2013), in Cyprus (51\%) (30), and in Italy (57\%) (2).

In this study, Goats of all ages are susceptible to analplasmosis, but the severity of the infection is directly related to the age, with older animals suffering more severe clinical disease. The relatively high seroprevalence (\%) was observed in age group above 3 years old as compared to other age groups. It has been reported that sheep and goats of all age's groups are susceptible to A. ovis infection, but older animals may suffer from a greater reduction in hematocrit values (17). Young animals probably become infected early, develop immunity and serve as reservoirs of infection for other animals (31). The results of the present study were completely in line with the findings of $(12,20)$, who reported that adult animals were more susceptible to anaplasmosis infection than younger animal. This finding indicated that adult goat may have more opportunities for exposure to ticks carrying the pathogen than younger animals. All together, the relatively high seroprevalence of Anaplasma ovis observed in present study could be due to the favorable environmental conditions especially in spring for the survival and proliferation of the tick vectors responsible for the transmission of the infectious disease since the goat are reared under extensive and semi-intensive 
management systems and it is likely that the pathogen contributes to economic losses to livestock industry. Additionally, the bacterium could also favor infections with other pathogenic infections as the immune system of $A$. ovis infected goat is weakened. Such differences also could be related to the size of sample from each herd and the time of the year the sampling was performed. One of the previous studies performed in Sicily-Italy comes to the conclusion that animals under poor healthy conditions may expose a higher infection rate and also contribute to multiple Anaplasma infections (32).

In this study, cELISA detected a higher number of infected animals with $A$. ovis $(n=61)$ than the Giemsa stained blood smear $(n=35)$. These discrepancies could be explained by differences in the timing of the parasite presence and the antibody responses in the infected goat as well as the stage of infection. During the chronic stage (long-term) of infection antibodies remain in the blood circulation for a longer period (up to 10 years after infection) even with low levels of parasitemia (31). Therefore, competitive ELISA based on major surface protein-5 has obvious advantage over other serological tests because of higher sensitivity $96 \%$ and specificity $95 \%$ for diagnosis of anaplasmosis (11).

Regarding hematological parameters of infected goats in the present study, a significant decrease was recorded in all analyzed hematological parameters; this indicates microcytic hypochrpmic anemia. Anemia in Anaplasmosis could be due to the extravascular hemolytic effect of anaplasmosis and phagocytosis of parasitized erythrocytes by reticuloendothelial system, primarily in spleen removal of the red blood cells rather than intravascular hemolysis accounts for the absence of hemoglobinemia and hemoglobinuria (33). The degree of anemia caused by an $A$. ovis infection is often more severe than that caused by a dominant parasitemia. The condition is characterized by the immune-mediated destruction of nonparasitized erythrocytes as well as parasitized erythrocytes, oxidative damage and poor antioxidant status (34). The same results were previously recorded by $(12,35)$. Yasini et al (36) also reported a macrocytic hypochromic anemia in sheep experimentally infected with $A$. ovis. In a study conducted by (37) hematological analysis of A. ovis-infected goats showed significant decreases in hemoglobin concentrations, RBC counts, and PCV values compared to the non-infected group of goat. These results were similar to the findings obtained in the present study.

To conclude, it can be stated that anaplamosis in small ruminants seems to be widely distributed in district Duhok, Kurdistan Region, Iraq. As small ruminants are a major source of milk, meat, hide and wool in several counties of the world, especially where the climate change is rather dry and hot weather and where pasture is scarce in most areas (38), there is an increasing demand for a better understanding of the diseases affecting these animals as they seem to contribute to a decrease in productivity. Several factors significantly influence the prevalence values determined by cELISA and blood smears, including the flock size, geographical origin of blood samples, livestock production system, grazing system and the evidence of clinical signs at the time of blood sampling. In fact, one of the recent studies reported that grazing system, vegetation cover, and livestock production system are also involved in the transmission of tick borne diseases including Anaplasma species (39). The cELISA appears to meet the criteria for use in diagnosing $A$. ovis infection in goats. The results of the present study for diagnosis of $A$. ovis in goat by cELISA analysis revealed that the traditional Giemsa staining method is not applicable for identification diagnosis of persistently infected goat. Anaplasma ovis can also causes marked hemolytic anemia that was microcytic hypochromic anemia especially during acute stage of infection. The findings this study would help in planning prevention and control strategies for Anaplasmosis in Kurdistam Region, Iraq. Further studies on tick born disease should be more focused on aspects related to the vector and this will be an important component in the study of epidemiology in Angora goats using advanced molecular techniques.

\section{Acknowledgment}

The author would like to thank Dr. Ihsan Kadir Zangana for his assistance in the diagnosis of Anaplasma ovis infection microscopically. The author declares that there is no conflict of interests.

\section{References}

1. de la Fuente J, Torina A, Caracappa S, Tumino G, Furl R, Almazn C, Kocan KM. Serologic and molecular characterization of Anaplasma species infection in farm animals and ticks from Sicily. Vet Parasitol. 2005; 133:357-362

2. Torina, A, Alongi A, Naranjo V, Scimeca S, Nicosia S, Di Marco, V, Caracappa, S, Kocan KM, de la Fuente J. Characterization of Anaplasma infections in Sicily, Italy. Ann NY Acad Sci. 2008;1149: 90-93.

3. De la Fuente J, Atkinson MW, NaranjoV, Fernandez de Mera IG, Mangold AJ, Keating KA, Kocan KM. Sequence analysis of the msp4 gene of Anaplasma ovis strains. Vet Microbiol. 2007;119:375-381.

4. Kocan KM, de la Fuente J, Guglielmone AA, Melendez RD. Antigens and alternatives for control of Anaplasma marginale infection in cattle. Clin Microbiol Rev. 2003;16:698-712.

5. Friedhoff KT.Tick-borne diseases of sheep and goats caused by Babesia, Theileria or Anaplasma spp. J Parassitol. 1997;39(Suppl 1):99-109

6. Kocan KM, de la Fuente J, Blouin EF, Coetzee JF, Ewing SA. The natural history of Anaplasma marginale. Vet Parasitol. 2010;167:95107.

7. MolloyJB, Bowles PM, Knowles DP. Comparison of a competitive inhibition ELISA and the card agglutination test for detection of 
antibodies to Anaplasma marginale and Anaplasma centrale in cattle. Aust Vet J. 1999; 77:245-249.

8. Duzgun A, Schuntner CA, Wright IG. A sensitive ELISA technique for the diagnosis of Anaplasma marginale infections. Vet Parasitol. 1988;29:1-7

9. Montenegro-James S, Guillen AT, Ma SJ. Use of the dot enzymelinked immunosorbent assay with isolated Anaplasma marginale initial bodies for serodiagnosis of anaplasmosis in cattle. Am J Vet Res. 1990;51:1518-1521

10. Scoles G, Goff W, Knowles DP. Validation of an Anaplasma marginale cELISA for use in diagnosis of $A$. ovis infections in domestic sheep and Anaplasma spp. in wild ungulates. Vet Microbiol. 2008;130:184-190.

11. Urdaz-Rodriguez JH, Fosgate GT, Alleman AR, Rae DO, Donvan GA, Melendez P. Seroprevalence estimation and management factors associated with high herd seropositivity for Anaplasma marginale in commercial dairy farms of Puerto Rico. Trop Anim Health Prod. 2009;41:1439-48.

12. Naqid IA, Zangana IZ. Hematological and serological (cELISA) studies of caprine anaplasmosis in Duhok governorate of Kurdistan region of Iraq. J Duhok Univ. 2011;13(1):153-161.

13. Meyer DJ, Harvey JW. Veterinary laboratory medicine. 3rd ed. WB. Saunders Co London. 2004;17- 24, 63-65, 163.

14. Jalali S, Khaki Z, Kazemi B, Bandehpour M, Rahbari S, Razi Jalali M, Yasini S. Molecular detection and identification of Anaplasma species in sheep from Ahvaz, Iran. Iranian J Vet Res. 2003;14(1):50-56.

15. Dreher UM, Fuente J, Hofmann-Lehmann R, Meli ML, Pusterla N, Kocan KM, Regula Z, Staerk KD, Lutz H.Serologic crossreactivity between Anaplasma marginale and Anaplasma phagocytophilum. Clin Diagn Lab Immunol.2005;12:1177-1183.

16. Goda ASA, Osman WA, Mona AM, Abou-Elnaga, TR. Seroprevalence of Anaplasma ovis antibodies in small ruminants by major surface protein 5 competitive inhibition enzyme-linked immunosorbent assay. Suez Canal Vet Med J. 2009;1:287-297.

17. Stoltsz WH. Ovine and caprine anaplasmosis. In: Coetzer, JAW and Tustin, RC (Eds.), Infectious diseases of livestock. (2nd Ed.), Cape Town, Oxford University Press. 2004;1:617-624.

18. Alsaad KM, Al-obaidi QT, Esmaeel SA. Hematological and biochemical study on the effect of some common blood parasites in native goats in Mosul area. Iraq. J Vet Sci. 2009;23:101-106.

19. Renneker S, Abdo J, Salih DEA, Karagenc T, Bilgi H, Torina A. Oliva AG, Campos J, Kullmann B, Ahmed J, Seitzer U. Can Anaplasma ovis in small ruminants be Neglected any longer? Transbound Emerg Dis. 2013;60:105-112.

20. Razmi GR, Dastjerdi K, Hosseini H, Naghibi A, Barati F, Aslani MR. An epidemiological study on Anaplasma infection in cattle, sheep, and goats in Mashhad suburb, Khorasan province, Iran Ann N Y Acad Sci. 2006;1078:479-481.

21. Ahmadi-Hamedani M, Khaki Z, Rahbari S, Kazemi B, Bandehpour M. Molecular identification of anaplasmosis in goats using a new PCR-RFLP method. Iranian J Vet Res. 2009;10:367-372.

22. Leger E, Vourc'h G, Vial L, Chevillon C, McCoy KD. Changing distributions of ticks: causes and consequences. Experi and Appl Acarology. 2013;59:219-244.

23. Al-Amerey MA, Hasso SA. Epizootiological Survey of some blood and fecal parasitic protozoa of goats around Baghdad City. Basrah J Vet Res. 2002;1(2):41-48.
24. Toye P, Handel I, Gray J, Kiara H, Thumbi S, Jennings A, Conradie van Wyk I, Ndila M, Woolhouse M, Bronsvoort M.Maternal antibody uptake, duration and influence on survival and growth rate in a cohort of indigenous calves in a small holder farming system in western Kenya. Vet Immunol Immunopath. 2013;155:129-134.

25. Ndung'u L, Aguirre WC, Rurangirwa FR, McElwain TF, McGuire TC, Knowles DP, Palmer GH. Detection of Anaplasma ovis infection in goats by major surface protein-5 competitive inhibition enzymelinked immunosorbent assay. J Clin Microbiol. 1999;33:675-679.

26. Coetzeea JF, Apleya MD, Kocan KM, Rurangirwac FR, Donkersgoed JV. Comparison of three oxytetracycline regimens for the treatment of persistent Anaplasma marginale infections in beef cattle. Vet Parasitol. 2005;127:61-73.

27. Noaman V, Shaya P. Comparison of microscopy and PCR-RFLP for detection of Anaplasma marginale in carrier cattle. Iran J Microbiol. 2010;2:89-94.

28. Maloo SH, Rowlands GJ, Thorpe W, Gettinby G, Perry BD. A longitudinal study of disease incidence and case-fatality risks on small-holder dairy farms in coastal Kenya. Preventive Vet Med. 2001;52:17-29.

29. Zhang G, Sun X, Zhao Y, Liu X, Zheng Z, Sun Y, R Liu. Prevalence of Anaplasma spp. infection in a desert landscape region of Heshuo, Xinjiang. Zhonghua Liu Xing Bing Xue Za Zhi. 2013;34:147-151.

30. Chochlakis, D, Ioannou I, Sharif L, Kokkini S, Hristophi N, Dimitriou T, Tselentis Y, Psaroulaki A. Prevalence of Anaplasma spp. in goats and sheep in Cyprus. Vector Borne Zoonotic Dis. 2009;9:457-463.

31. Herrero MV, Perez E, Goff WL, Torioni de Echaide S, Knowles DP, McElwain TF, Buening GM. Prospective study for the detection of Anaplasma marginale Theiler, 1911 (Rickettsiales: Anaplasmataceae) in Coasta Rica. Annals of the New York Aca Sci. 1998;849:226-233.

32. Torina, A, Galindo RC, Vicente J, Di Marco V, Russo M, Aronica V, Fiasconaro M, Scimeca S, Kocan C, de la Fuente J. Characterization of Anaplasma phagocytophilum and A. ovis infection in a naturally infected sheep flock with poor health condition. Trop Anim Health Prod. 2010;42:1327-1331.

33. Latimer KS, Mahaffey EA, Prasse KW. Veterinary Laboratory Medicine, Clinical Pathology. (4th ed.) Iowa State Press, Iowa, USA, 2003.

34. De U, Dey S, Banerjee P, Sahoo M. Among Anaplasma marginale parasitemia and markers of oxidative stress in crossbred calves. Trop Anim Health Prod. 2012;44:385-388.

35. Bell-Sakyia L, Koneya EBM, Dogbeya O, Walkerb AR. Emergence and genetic variability of Anaplasma species in small ruminants and ticks from Central Europe. Vet Parasitol. 2004;4:25-42.

36. Yasini SP, Khaki Z, Rahbari S, Salar-Amoli J, Gharabaghi A, Jalali SM. Hematologic and clinical aspects of experimental ovine anaplasmosis caused by Anaplasma ovis. Iran J Parasitol. 2012;7:9198.

37. Ahmadi-hamedani M, Khaki Z, Rahbari S, Ahmadi-Hamedani MA. Hematological profiles of goats naturally infected with Anaplasma ovis in North and Northeast Iran. Comp Clin Pathol. 2012;21(6):11791182.

38. Sherman DM. The spread of pathogens through trade in small ruminants and their products. Rev Sci Tech. 2011;30(1):207-217

39. Liu Z, Ma M, Wang Z, Wang J, Peng Y, Li Y, Guan G, Luo J, Yin H. Molecular survey and genetic identification of Anaplasma species in goats from central and Southern China Appl Environ Microbiol. 2012;78;464-470. 